\title{
Reasons for Workplace Mental Illness Disclosure and Non-Disclosure in Japan
}

\author{
Hatsumi Yoshii \\ School of Health Sciences, Tohoku University Graduate School of Medicine, Miyagi, Japan \\ Email: hatsumi@med.tohoku.ac.jp
}

Received 2 June 2014; revised 12 July 2014; accepted 23 July 2014

Copyright (C) 2014 by author and Scientific Research Publishing Inc. This work is licensed under the Creative Commons Attribution International License (CC BY). http://creativecommons.org/licenses/by/4.0/

\section{Abstract}

The employment of people with mental illness is increasing each year in Japan. When they choose regular employment, some choose to disclose their illness, and others do not. In this qualitative study in Japan, I conducted a questionnaire survey among people with mental illness with an employment history about their experiences with disclosing their mental illness. After the data were coded, categorized, and analyzed, I identified three common factors for non-disclosure to an employer or supervisor: anxiety about dismissal and not being hired, anxiety about unfavorable treatment, and anxiety about stigma. Education and consideration for the illness were identified as requests for the employer. Based on these findings, I concluded that people with mental illness anticipate social alienation at the time of hiring or while they are on the job, that they must take measures to improve their working environment and decrease stigma in the workplace to continue working, and that education and increased awareness of mental illness in the workplace are needed.

\section{Keywords}

Disclose, Mental Illness, Reason

\section{Introduction}

In fiscal year 2012 in Japan, the number of people with disabilities employed at private companies reached a record high of 382,363 with the employment of people with mental disabilities showing a considerable increase of 27.8\% over the previous year [1]. The Handicapped Person's Employment Promotion Law (revised), enacted on June 19, 2013, primarily mandates that people with mental disabilities are added to the calculation bases of the employment rate for people with disabilities. The employment of people with mental illness in Japan is expected to continue to increase in the future. When people with mental illness choose normal employment, rather 
than employment through handicapped hiring quotas, some choose to disclose their illness, and others do not. What accounts for this difference? It seems reasonable to assume that those who disclose their illness want their work to proceed smoothly and request their employers to show consideration for their conditions, whereas those who do not disclose their illness want to avoid the low wages and poor working conditions associated with the stigma of mental illness.

\section{Literature Review}

Mental disorders are a significant cause of disability and loss of workplace productivity [2]. The number of people with mental disorders leaving vocational facilities and seeking employment in the ordinary workplace is much higher than the numbers of people with cognitive impairments or physical disabilities [3]. Fear of discrimination and legal, practical, and moral pressures have been shown to contribute to the tension between workplace disclosure and non-disclosure of a mental illness [4]. Additionally, people with mental disorders have commonly suffered from stigma following the disclosure of their illness [5]. Past work has indicated that anticipated discrimination by employers also presents a barrier to seeking mental health care [6]. People with mental disorders might actively reject the opportunity to work or stop looking for work in anticipation of prejudice toward them. This would indicate that users of mental health services face difficulties in deciding whether to disclose a mental health problem to an employer [7]. The present study investigated workplace mental illness disclosure, which had not yet been explored in Japan.

\section{Study Aim}

In this study, I conducted a questionnaire survey among people with mental illness with a history of employment to investigate their experiences of disease disclosure. The hope is that the results will help to create guidelines for support workers to manage the unavoidable problems associated with illness disclosure when providing career support to people with mental illness. The results are also expected to provide evidence that will benefit companies and society in general by contributing to building a society where people with mental illness can work without the need to hide their illness.

\section{Methods}

\subsection{Participants}

Participants were 69 patients with mental illness with an employment history who were inpatients in an open ward of psychiatric hospital A, outpatients of the hospital's clinic, or users of the hospital's day care center. Participant selection was implemented by the administrator of each facility, and participants who provided informed consent were enrolled in the study. The mental condition of all participants was stable because of continued regular medication, and none had problems with language, literacy, or thinking relevant to answering the study questionnaire.

\subsection{Questionnaire Survey}

In the questionnaire, patients wrote answers to three open-ended questions concerning 1) the reasons for disclosing or not disclosing their illness to their employer at the time of hiring, 2) the reasons for disclosing or not disclosing their illness to their supervisor and coworkers while they were on the job, and 3) requests for their employer to enable them to do their job smoothly.

\subsection{Data Analysis}

The data analysis was conducted using a method similar to that used by Indratula et al. [8]. Conventional content analysis, in which categories are directly extracted from textual data, was used to identify categories and themes in the data. Words and sentences expressing central meaning units were identified, and data were systematically condensed without changing the original meaning. Meaning units were labeled with codes, which were then sorted into categories and subcategories according to the similarities and differences between them. Iterative analysis was performed on the whole texts, codes, and categories. An interpretation of the underlying meaning that permeated the categories was formulated into themes. 


\subsection{Ethical Considerations}

This study was conducted with the approval of the Ethics Review Board of Tohoku University Medical Science Postgraduate School and the participating hospital. All participants provided informed consent after receiving verbal and written explanations of the study, including the assurance that their participation would be kept confidential, that they could withdraw from the study at any time, and that all data would be handled anonymously and used for research purposes only.

\section{Results}

\subsection{Participants' Demographic Characteristics}

The largest percentage of participants (36.2\%) were in their 40s, and $75.4 \%$ were men. In terms of educational background, the largest group consisted of high school graduates (40.6\%). Almost half of the participants were diagnosed with schizophrenia, and $76.8 \%$ of all participants had been hospitalized in a psychiatric hospital. Across different types of workplaces, $63.8 \%$ worked as regular employees, and 23.2\%were part-time employees. The most frequently reported employment sector was the service industry (36.2\%). Most participants (66.0\%) did not disclose their illness to their employer at the time of hiring, and most did not disclose their illness to their supervisor while they were on the job (58.0\%). Additionally, 42.0\% of the participants recounted experiences of being treated differently by other people in the workplace (Table 1).

\subsection{Disclosure and Non-Disclosure to the Employer during Hiring}

Based the analysis of the data collected, I extracted four categories of reasons for non-disclosure at the time of hiring: anxiety about not being hired, anxiety about unfavorable treatment, lack of awareness of illness, and not feeling the need to disclose (Table 2).

I extracted two categories of reasons for disclosure at the time of hiring: disclosure to continue working and disclosure by other people (Table 3).

\subsection{Disclosure and Non-Disclosure to the Supervisor While on the Job}

I extracted seven categories of reasons for non-disclosure to supervisors: anxiety about dismissal, anxiety about stigma, anxiety about unfavorable treatment, not feeling the need to disclose, anxiety about violation of privacy, lack of awareness of illness, and no chance to talk (Table 4).

I extracted four categories of reasons for disclosure to supervisors: disclosure out of necessity, desire to be understood, disclosure to continue working, and disclosure by other people (Table 5).

\subsection{Disclosure and Non-Disclosure to Coworkers While on the Job}

I extracted eight categories of reasons for non-disclosure to coworkers: anxiety about stigma, potential obstacles at work if disclosed, anxiety about dismissal, lack of awareness of illness, consideration of human relationships, not feeling the need to disclose, anxiety about violation of privacy, and no chance to talk (Table 6).

I extracted three categories for disclosure to coworkers: desire to be understood, disclosure by other people, and disclosure to continue working (Table 7).

\subsection{Requests for Employers}

I extracted five categories of requests for employers: education, measures taken to cope with stigma, improved treatment, consideration for the illness, and readiness to work (Table 8).

\section{Discussion}

\subsection{Anxiety about Dismissal, Not Being Hired, and Unfavorable Treatment}

Disclosure of illness is a major problem for people with mental disorders [7]. The finding of the present study that should be emphasized is that anxiety about dismissal, not being hired, and anxiety about unfavorable treatment were common factors underlying the reasons why people with mental illness do not disclose their illness to 
Table 1. Demographic characteristics of participants.

\begin{tabular}{|c|c|c|}
\hline Age & Number & $\%$ \\
\hline $20 \mathrm{~s}$ & 2 & 2.9 \\
\hline 30 s & 8 & 11.6 \\
\hline $40 \mathrm{~s}$ & 25 & 36.2 \\
\hline $50 \mathrm{~s}$ & 19 & 27.5 \\
\hline 60s and Older & 15 & 21.7 \\
\hline \multicolumn{3}{|l|}{ Gender } \\
\hline Male & 52 & 75.4 \\
\hline Female & 17 & 24.6 \\
\hline \multicolumn{3}{|l|}{ Educational Background } \\
\hline Junior High School & 5 & 7.2 \\
\hline High School & 28 & 40.6 \\
\hline Vocational School & 13 & 18.8 \\
\hline Junior College & 4 & 5.8 \\
\hline University or Graduate School & 18 & 26.1 \\
\hline Other & 1 & 1.4 \\
\hline \multicolumn{3}{|l|}{ Disorder } \\
\hline Schizophrenia & 34 & 49.3 \\
\hline Depression & 13 & 18.8 \\
\hline Alcoholism & 6 & 8.7 \\
\hline Bipolar Disorder & 9 & 13.0 \\
\hline Other & 7 & 10.1 \\
\hline \multicolumn{3}{|l|}{ Number of Hospitalizations in Psychiatric Hospitals } \\
\hline 0 & 16 & 23.2 \\
\hline 1 & 18 & 26.1 \\
\hline $2-4$ & 20 & 29.0 \\
\hline $5-9$ & 7 & 10.1 \\
\hline 10 or More & 8 & 11.6 \\
\hline \multicolumn{3}{|l|}{ Job Description } \\
\hline Clerical Work/Computer & 8 & 11.6 \\
\hline Medical/Welfare & 7 & 10.1 \\
\hline Services & 25 & 36.2 \\
\hline Education & 8 & 11.6 \\
\hline Manufacturing/Construction/Agriculture/Forestry/Fishery & 14 & 20.3 \\
\hline Other & 7 & 10.2 \\
\hline \multicolumn{3}{|l|}{ Type of Employment } \\
\hline Regular Employee & 44 & 63.8 \\
\hline Part-Time Employee & 16 & 23.2 \\
\hline Self-Employed/Manager & 4 & 5.8 \\
\hline Temporary/Contract/Junior/Dispatched Worker & 3 & 4.3 \\
\hline Other & 2 & 2.9 \\
\hline \multicolumn{3}{|c|}{ Experience Being Treated Differently by Other People in the Workplace } \\
\hline Yes & 29 & 42.0 \\
\hline No & 37 & 53.6 \\
\hline Don’t Know & 3 & 4.4 \\
\hline
\end{tabular}


Table 2. Reasons not to disclose mental illness to the employer at the time of hiring.

\begin{tabular}{ll}
\hline \multicolumn{1}{c}{ Categories } & \multicolumn{1}{c}{ Codes } \\
\hline & Thought I wouldn't be hired. \\
Because I thought I wouldn't be hired. \\
I wouldn't be hired if I disclosed the illness. \\
Thought I wouldn't be hired. \\
Because it was possible I wouldn't be hired. \\
Because I wouldn't be hired if I disclosed the disease. \\
I thought I would be fired. \\
I wanted to be employed. \\
I didn't want to fail. \\
I would be in trouble if I was turned down. \\
I thought I wouldn't be hired if I disclosed it. \\
I was denied when I disclosed the disease before. \\
I thought I wouldn't be hired. \\
Thought I'd be disadvantaged. \\
Because then I wouldn't get high wages. \\
I thought I would have poorer working conditions or wages. \\
I wasn't aware. \\
Anxiety about unfavorable treatment. \\
Lack of awareness of illness \\
I didn't tell because there was no need to disclose the disease. \\
Not feeling the need to disclose
\end{tabular}

\section{Table 3. Reasons to disclose mental illness to the employer at the time of hiring.}

\begin{tabular}{ll}
\hline \multicolumn{1}{c}{ Categories } & \multicolumn{1}{c}{ Codes } \\
\hline $\begin{array}{ll}\text { Disclosure to continue working } \\
\text { Disclosure by other people }\end{array}$ & Work entails certain aptitudes (Each man is useful in his own way). \\
\hline
\end{tabular}

Table 4. Reasons not to disclose mental illness to the supervisor while on the job.

\begin{tabular}{|c|c|}
\hline Categories & Codes \\
\hline \multirow{5}{*}{ Anxiety about dismissal } & Because I thought I'd be dismissed. \\
\hline & I thought the employer would fire me. \\
\hline & I wouldn’t be employed if I told. \\
\hline & I might be fired. \\
\hline & Might well be fired. \\
\hline \multirow{8}{*}{ Anxiety about stigma } & Those around would look at me strangely or I would be discriminated against. \\
\hline & Because I would be looked at with prejudice. \\
\hline & I was afraid I would be misunderstood. \\
\hline & Because I would be made a fool of or watched with prejudice. \\
\hline & I didn’t want my boss to be prejudiced without reason. \\
\hline & I’m ashamed. \\
\hline & Likely to be treated with prejudice (as a nurse). \\
\hline & Thought I would be looked at strangely. \\
\hline Anxiety about unfavorable treatment & Because I thought I wouldn’t be treated considerately as a handicapped person. \\
\hline \multirow{2}{*}{ Not feeling the need to disclose } & I thought it was unnecessary to disclose it because the disorder has nothing to do with work. \\
\hline & I think it's unnecessary \\
\hline Anxiety about violation of privacy & My personal information might be disclosed to others. \\
\hline Lack of awareness of illness & I didn't recognize it was an illness then. \\
\hline No chance to talk & I was so shocked myself that there was simply no question of telling someone. \\
\hline
\end{tabular}


Table 5. Reasons to disclose mental illness to the supervisor while on the job.

\begin{tabular}{|c|c|}
\hline Categories & Codes \\
\hline \multirow{5}{*}{ Disclosure out of necessity } & Because I needed to be leave work temporarily. \\
\hline & Because I had to take a few days off. \\
\hline & I thought I had to quit, and it was necessary to explain the reason. \\
\hline & I got the disorder during work. \\
\hline & My supervisor pointed it out. \\
\hline Desire to be understood & Because I want to be understood. \\
\hline Disclosure to continue working & Because a transfer was proposed for me. \\
\hline Disclosure by other people & My professor at the university told the president of the company when I got the job. \\
\hline Categories & Codes \\
\hline \multirow{6}{*}{ Anxiety about stigma } & I'm ashamed. \\
\hline & Because I thought I would be looked at strangely. \\
\hline & I was ashamed. I was embarrassed. \\
\hline & Because then I would be made fun of or watched with prejudice. \\
\hline & If I told, I would be made fun of or laughed at. \\
\hline & Likely to be treated with prejudice (as a nurse). \\
\hline Potential obstacles at work if disclosed & Disclosure might cause problems for me at work. \\
\hline Anxiety about dismissal & I thought a sick pharmacist couldn't continue working. \\
\hline Lack of awareness of illness & I wasn’t aware. \\
\hline \multirow{2}{*}{ Consideration of human relationships } & If I told, people would be embarrassed. \\
\hline & I didn’t want to be bothered. \\
\hline \multirow{7}{*}{ Not feeling the need to disclose } & No need. \\
\hline & I didn't particularly want to talk about it. \\
\hline & I don't feel the need. \\
\hline & I didn't feel the need to tell because I was treated like all the others. \\
\hline & I thought people would understand me if I didn't tell. \\
\hline & My illness was not so severe. \\
\hline & I wanted to keep it a secret for a while. \\
\hline \multirow{2}{*}{ Anxiety about violation of privacy } & My privacy might be disclosed to other people. \\
\hline & If I told one trustworthy person, the information would surely spill out to others. \\
\hline No chance to talk & I was so shocked myself that there was simply no question of telling someone. \\
\hline
\end{tabular}

Table 7. Reasons to disclose mental illness to coworkers while on the job.

\begin{tabular}{ll}
\hline \multicolumn{1}{c}{ Categories } & \multicolumn{1}{c}{ Codes } \\
\hline Desire to be understood & As I became great friends with this person, I really wanted this person to understand me. \\
& I want to be understood. \\
Disclosure by other people & Someone told people at the workplace after I was hospitalized. \\
Disclosure to continue working & Everyone in my company knew that. \\
\hline
\end{tabular}


Table 8. Requests for the employer.

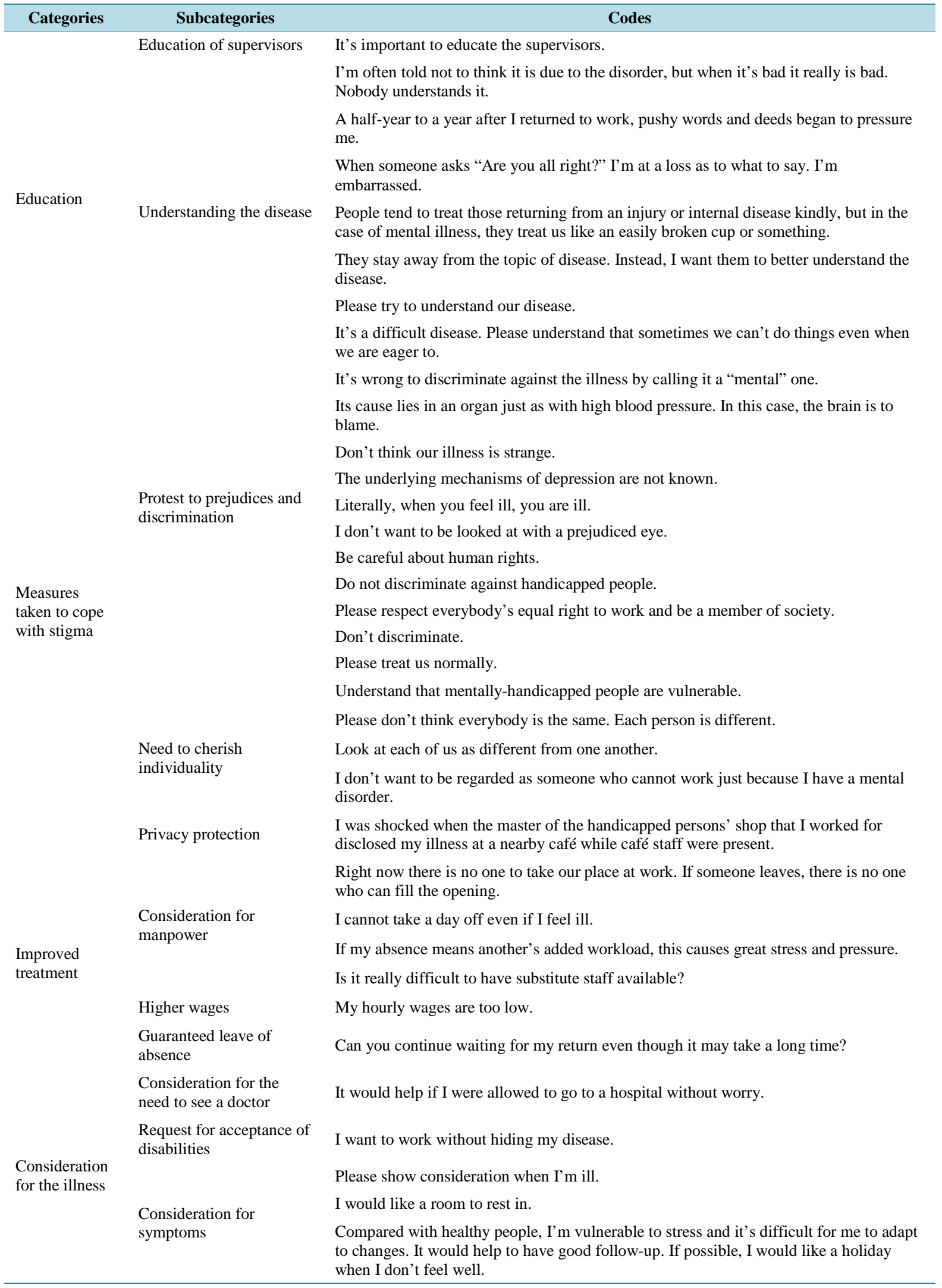




\section{Continued}

\begin{tabular}{lll}
\hline & $\begin{array}{l}\text { I want to do whatever I } \\
\text { can }\end{array}$ & Please let me do the work I can do even if I'm a handicapped person. \\
$\begin{array}{l}\text { Readiness to } \\
\text { work }\end{array}$ & $\begin{array}{l}\text { I want to work even for } \\
\text { low wages }\end{array}$ & $\begin{array}{l}\text { I want to work because I want to earn money to help support myself. It may be daily or } \\
\text { monthly. It may be paid according to the time I work. It may even be below minimum } \\
\text { wage. }\end{array}$
\end{tabular}

their employer or supervisor at the time of hiring or while on the job. Many studies in and outside of Japan have reported that $80 \%$ - 90\% of people with mental illness are unemployed [9]-[13]. In their literature review, Laxman et al. [14] revealed that, in North America, the careers of people with borderline personality disorder were disrupted by dismissals, delayed or withheld promotions, demotions, or other events. Also, in an interview study of bipolar disorder patients, several respondents reported dismissals, delayed or withheld promotions, or demotions after they disclosed their disability [15]. Likewise, I expected that the participants in this survey would not disclose their illness owing to the prospect of such disadvantages. In other words, people with mental illness anticipate being socially alienated at the time of hiring or while on the job.

\subsection{Anxiety about Stigma}

I would also like to call special attention to anxiety about stigma, which was one of the reasons for non-disclosure to a supervisor or coworkers while on the job. Stigma is defined as a majority group in society making a negative evaluation of a minority group [16] [17]. People with mental illness generally internalize abusive or discriminatory societal attitudes. The lower they believe they are being evaluated, the more they fear interaction with others, and they defend themselves by hiding their illness, withdrawing from the community, or anticipating discrimination by refusing to be around others [18]. Angermeye and Matschinger [19] recognized the stigma felt by people with mental illness as an obstacle to creating a society where both handicapped and non-handicapped people can live together, or normalization. In connection with this, Stuart [20] found that $78 \%$ of people with mental illness in Canada have felt stigma while at work. Moreover, in an interview survey targeted at patients with bipolar disorder, Michalak et al. [15] found that half of the respondents reported workplace stigma. The present study also found that people with mental illness experience being treated differently by other people in the workplace too (Table 1). Bender and Farvolden [21] described stigma experienced by patients with manic depression. Thus, many studies have reported that people with mental illness feel stigma in the workplace. Such situations are attributed to unsatisfactory working environments for people with mental illness [20]. Participants in the present study also felt anxious in anticipation of workplace stigma, creating a situation in which stigma prevents them from disclosing their illness. Anxiety that stigma after illness disclosure might lead to dismissal, delayed or withheld promotions, or demotions can result in psychological isolation at work owing to hiding the mental disorder, avoiding contact with other people, disliking social activities, and withdrawing from the workplace. Those who react to stigma by minimizing their interaction with society will furthermore inhibit their adjustment to society, slow their recovery, and tend to become isolated. These occurrences have a negative impact on their work, income, social status, and self-evaluation [22]. In this study, one request for employers mentioned was taking measures to cope with stigma. For people with mental illness to continue working, such measures must be taken to decrease workplace stigma.

\subsection{Workplace Education about Mental Illness}

The identification of education and consideration for the illness as requests by people with mental illness for their employers indicates that strengthening mental health education and public awareness is needed, especially in the workplace. In Japan, education about mental disorders targeted at employers in general is insufficient, and employers have not gained adequate knowledge or learned effective strategies for coping with these disorders. Without adequate mental health literacy, people are at a loss as to how to deal with people with mental illness; they cannot understand the necessary considerations. It is generally thought that stigma decreases when the diseases and the patients are understood [23]. A lack of knowledge can lead to stigma, so the spread and promotion of knowledge are urgently needed. 


\subsection{Illness Disclosure and Career Advice for People with Mental Illness}

In Japan, various types of support are available for individuals with mental illness in the community, but this mainly involves medical care. Workplace support systems for these individuals, to say nothing of ways to support their illness disclosure, have not been established. Creating a support framework is necessary, because leaving illness disclosure to the person concerned without providing them with support will hinder prompt intervention and potentially lead to discontinued employment. Organization is needed to raise the employment rates of people with mental illness and to strengthen workplace support for them. This includes not only employers' efforts at gaining knowledge about mental disorders and mastering how to manage people with mental illness, but also an improved organizational framework in which people with mental illness themselves can continue working and manage their illness at the same time. In other words, employers would be asked to create a workplace environment in which measures are taken to decrease discrimination so that employees can easily discuss their illness as well as work without having to disclose it. In this study, disclosure by other people was identified as a reason for disclosing mental illness. This implies that other people reported the illness in the workplace even when the person concerned did not intend to do so. Disclosure out of necessity and disclosure to continue working were also identified reasons, clearly indicating that people with mental illness are sometimes forced to disclose their illness against their will to continue working.

\section{Conclusion}

Taken together, all of the findings to date highlight the following needs: to understand the feelings of people with mental illness and make workplace support available for them, to use and coordinate social resources, to increase opportunities for private consultation and communication with people with mental illness, and to set up and maintain a system for carrying out and following up on all of these needs.

\section{Acknowledgements}

This work was supported by a 2014 The Uehiro Foundation on Ethics and Education, entitled "The Problem of Stigma toward People with Mental disorder in the Workplace”.

\section{References}

[1] Ministry of Health, Labor and Welfare. Results of the Count of Employment Situation of Handicapped People in 2012. http://www.mhlw.go.jp/stf/houdou/2r9852000002o0Qm-att/241114houkoku.pdf

[2] Reavley, N.J., Ross, A., Killackey, E.J. and Jorm, A.F. (2012) Development of Guidelines to Assist Organisations to Support Employees Returning to Work after an Episode of Anxiety, Depression or a Related Disorder: A Delphi Consensus Study with Australian Professionals and Consumers. BMC Psychiatry, 3, 12-135.

[3] Brohan, E. and Thornicroft, G. (2010) Stigma and Discrimination of Mental Health Problems: Workplace Implications. Occupational Medicine, 60, 414-415. http://dx.doi.org/10.1093/occmed/kqq048

[4] Peterson, D., Currey, N. and Collings, S. (2011) “You Don’t Look Like One of Them”: Disclosure of Mental Illness in the Workplace as an Ongoing Dilemma. Psychiatric Rehabilitation Journal, 35, 145-147. http://dx.doi.org/10.2975/35.2.2011.145.147

[5] Chen, F.P., Lai, G.Y. and Yang, L. (2013) Mental Illness Disclosure in Chinese Immigrant Communities. Journal of Counseling Psychology, 60, 379-391. http://dx.doi.org/10.1037/a0032620

[6] Clement, S., Brohan, E., Jeffery, D., Henderson, C., Hatch, S. and Thornicroft, G. (2012) Development and Psychometric Properties of the Barriers to Access to Care Evaluation Scale (BACE) Related to People with Mental Ill Health. BMC Psychiatry, 12, 36. http://dx.doi.org/10.1186/1471-244X-12-36

[7] Brohan, E., Henderson, C., Wheat, K., et al. (2012) Systematic Review of Beliefs, Behaviors and Influencing Factors Associated with Disclosure of a Mental Health Problem in the Workplace. BMC Psychiatry, 16, 11-12. http://dx.doi.org/10.1186/1471-244X-12-11

[8] Indratula, R., Sukonthasarn, A., Chanprasit, C. and Wangsrikhun, S. (2013) Experiences of Thai Individuals Awaiting Coronary Artery Bypass Grafting: A Qualitative Study. Nursing \& Health Sciences, 15, 474-479. http://dx.doi.org/10.1111/nhs.12058

[9] Crowther, R.E., Marshall, M., Bond, G.R. and Huxley, P. (2001) Helping People with Severe Mental Illness to Obtain Work: Systematic Review. British Medical Journal, 322, 204-208. http://dx.doi.org/10.1136/bmj.322.7280.204

[10] Dalgin, R.S. and Gilbride, D. (2003) Perspectives of People with Psychiatric Disabilities on Employment Disclosure. 
Psychiatric Rehabilitation Journal, 26, 306-310. http://dx.doi.org/10.2975/26.2003.306.310

[11] Drake, R.E., Fox, T.S., Leather, P.K., et al. (1998) Regional Variation in Competitive Employment for Persons with Severe Mental Illness. Administration and Policy in Mental Health, 25, 493-504. http://dx.doi.org/10.1023/A:1022337231689

[12] Krupa, T., Lagarde, M. and Carmichael, K. (2003) Transforming Sheltered Workshops into Affirmative Businesses: An Outcome Evaluation. Psychiatric Rehabilitation Journal, 26, 359-367. http://dx.doi.org/10.2975/26.2003.359.367

[13] McQuilken, M., Zahniser, J.H., Novak, J., Starks, R.D., Olmos, A. and Bond, G.R. (2003) The Work Project Survey: Consumer Perspectives on Work. Journal of Vocational Rehabilitation, 18, 59-68.

[14] Laxman, K.E., Lovibond, K.S. and Hassan, M.K. (2008) Impact of Bipolar Disorder in Employed Populations. The American Journal of Managed Care, 14, 757-764.

[15] Michalak, E.E., Yatham, L.N., Maxwell, V., Hale, S. and Lam, R.W. (2007) The Impact of Bipolar Disorder upon Work Functioning: A Qualitative Analysis. Bipolar Disorder, 9, 126-143. http://dx.doi.org/10.1111/j.1399-5618.2007.00436.x

[16] Byrne, P. (2000) Stigma of Mental Illness and Ways of Diminishing It. Advances in Psychiatric Treatment, 6, 65-72. http://dx.doi.org/10.1192/apt.6.1.65

[17] Corrigan, P.W., Larson, J.E. and Rusch, N. (2009) Self-Stigma and the "Why Try" Effect: Impact on Life Goals and Evidence-Based Practices. World Psychiatry, 8, 75-81.

[18] Ertugrul, A. and Ulug, B. (2004) Perception of Stigma among Patients with Schizophrenia. Social Psychiatry and Psychiatric Epidemiology, 39, 73-77. http://dx.doi.org/10.1007/s00127-004-0697-9

[19] Angermeyer, M.C. and Matschinger, H. (1997) Social Distance towards the Mentally Ill: Results of Representative Surveys in the Federal Republic of Germany. Psychological Medicine, 27, 131-141. http://dx.doi.org/10.1017/S0033291796004205

[20] Stuart, H. (2004) Stigma and Work. Healthcare Papers, 5, 100-111. http://dx.doi.org/10.12927/hcpap..16829

[21] Bender, A. and Farvolden, P. (2008) Depression and the Workplace: A Progress Report. Current Psychiatry Reports, 10, 73-79. http://dx.doi.org/10.1007/s11920-008-0013-6

[22] Berge, M. (2005) Self-Esteem and Stigma among Persons with Schizophrenia. Implications for Mental Health. Care Management Journals, 6, 139-144. http://dx.doi.org/10.1891/cmaj.6.3.139

[23] Papadopoulos, C., Leavey, G. and Vincent, C. (2002) Factors Influencing Stigma. Social Psychiatry and Psychiatric Epidemiology, 37, 430-434. http://dx.doi.org/10.1007/s00127-002-0560-9 
Scientific Research Publishing (SCIRP) is one of the largest Open Access journal publishers. It is currently publishing more than 200 open access, online, peer-reviewed journals covering a wide range of academic disciplines. SCIRP serves the worldwide academic communities and contributes to the progress and application of science with its publication.

Other selected journals from SCIRP are listed as below. Submit your manuscript to us via either submit@scirp.org or Online Submission Portal.
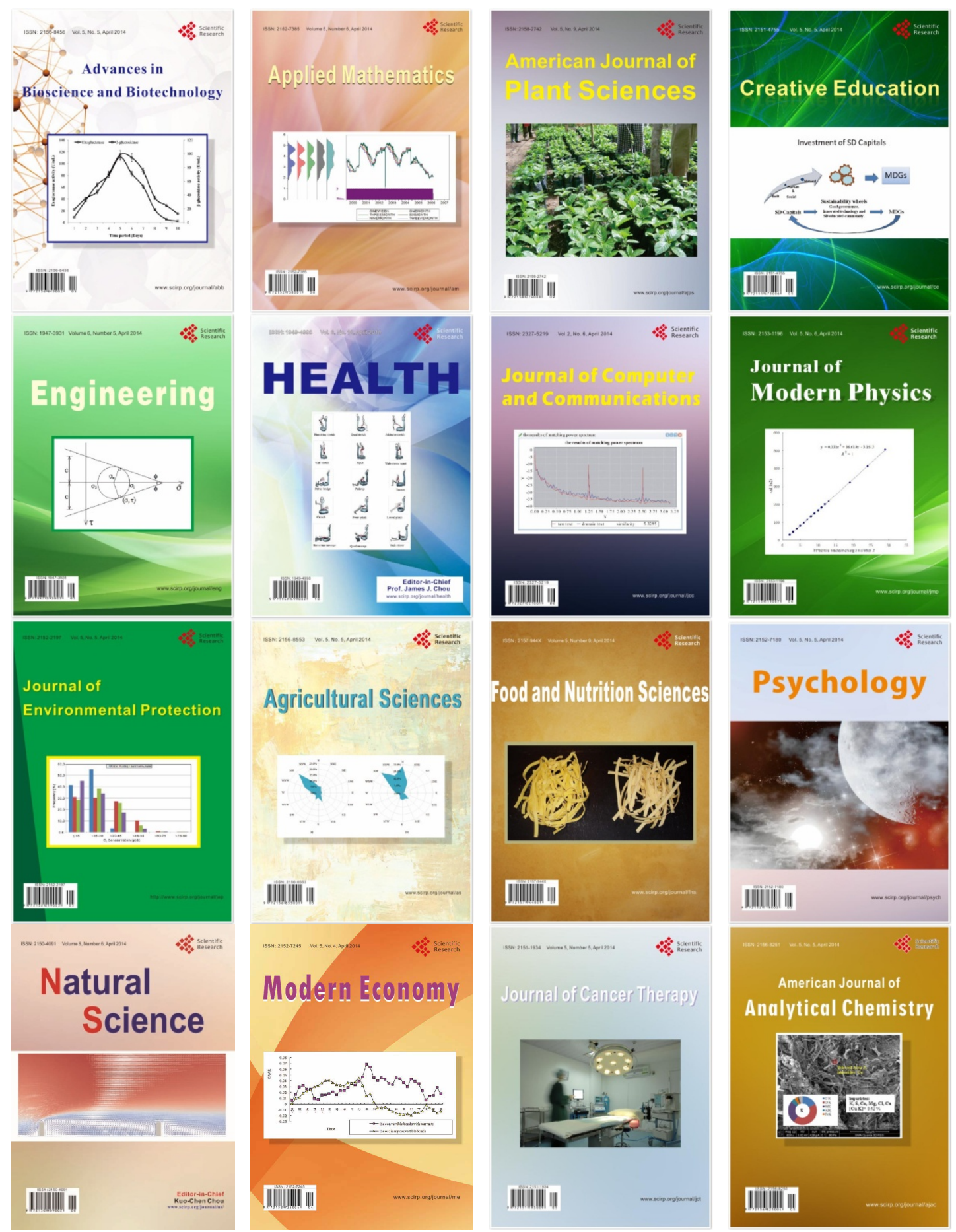